\title{
Present and future Laurentian Great Lakes hydroclimatic conditions as simulated by regional climate models with an emphasis on Lake Michigan-Huron
}

\author{
Biljana Music • Anne Frigon • Brent Lofgren • \\ Richard Turcotte $\cdot$ Jean-François Cyr
}

Received: 18 March 2014 / Accepted: 31 January 2015 / Published online: 6 March 2015

C) The Author(s) 2015. This article is published with open access at Springerlink.com

\begin{abstract}
Regional climate modelling represents an appealing approach to projecting Great Lakes water supplies under a changing climate. In this study, we investigate the response of the Great Lakes Basin to increasing greenhouse gas and aerosols emissions using an ensemble of sixteen climate change simulations generated by three different Regional Climate Models (RCMs): CRCM4, HadRM3 and WRFG. Annual and monthly means of simulated hydrometeorological variables that affect Great Lakes levels are first compared to observation-based estimates. The climate change signal is then assessed by computing differences between simulated future (2041-2070) and present (1971-1999) climates. Finally, an analysis of the annual minima and maxima of the Net Basin Supply (NBS), derived from the simulated NBS components, is conducted using Generalized Extreme Value distribution. Results reveal notable model differences in simulated water budget components throughout the year, especially for the lake evaporation component. These differences are reflected in the resulting NBS. Although uncertainties in observation-based estimates are quite large, our analysis indicates that all three RCMs tend to underestimate NBS in late summer and fall, which is related to biases in simulated runoff, lake evaporation, and over-lake precipitation. The climate change signal derived from the total ensemble mean indicates no change in future mean annual NBS. However, our analysis suggests an amplification of the NBS annual cycle and an intensification of the annual NBS minima in future climate. This emphasizes the need for an adaptive management of water to minimize potential negative implications associated with more severe and frequent NBS minima.
\end{abstract}

Electronic supplementary material The online version of this article (doi:10.1007/s10584-015-1348-8) contains supplementary material, which is available to authorized users.

B. Music $(\bowtie) \cdot$ A. Frigon

Ouranos - Consortium on Regional Climatology and Adaptation to Climate Change, 550 Sherbrooke West, West Tower, 19th floor Montreal, QC H3A 1B9, Canada

e-mail: music.biljana@ouranos.ca

B. Lofgren

NOAA/Great Lakes Environmental Research Laboratory, 4840 S. State Rd., Ann Arbor, MI 48108, USA

R. Turcotte $\cdot$ J.-F. Cyr

Centre d'Expertise Hydrique du Québec (CEHQ), 675 René-Lévesque Est, Québec, QC G1R 5V7, Canada 


\section{Introduction}

Over the last decades, there has been growing concern about the hydrological responses of the Great Lakes to global warming, stemming from potential changes in Great Lakes water level variability and the frequency of extremes under an evolving climate. Many of the historical studies addressing this issue are based on the so-called "change factor" method, which is typically applied to a suite of models known as the Advanced Hydrologic Prediction System (AHPS; e.g., Croley 1990; Hartmann 1990; Lofgren et al. 2002; Angel and Kunkel 2010; Hayhoe et al. 2010). The change factors in climate variables, typically derived from different Global Climate Model (GCM) projections, serve to perturb observed historical time series. Perturbed time series are then used as input to the AHPS, which compute future time sequences of the Great Lakes Net Basin Supply (NBS). The NBS is the primary driver of the Great Lakes levels. These can be derived by applying the latest version of Great Lakes Channel Routing and Regulation model (Hartmann 1988) using the NBS time sequences as input. The NBS is defined as the sum of the net atmospheric supply of water (that is the difference between precipitation that falls into the lakes and evaporation from lakes) and the supply from the land through the Great Lakes' tributary streams (i.e., runoff). A comprehensive overview of the AHPS modeling system is provided in Gronewold et al. (2011). It is important to highlight that AHPS is primarily intended for seasonal forecasting, and not necessarily for longer-term climate-scale projections, in which energy and water budget conservation play an important role.

Climate change (CC) studies based on the above approach resulted in widespread belief that water supplies in the Great Lakes would inevitably decline. For example, early studies considering GCM projections under the $2 \mathrm{xCO}_{2}$ atmospheric scenarios report a 23 to $51 \%$ reduction in NBS and a decrease in lake levels ranging from 0.5 to $2.5 \mathrm{~m}$ (Croley 1990; Hartmann 1990). Similarly, a study by Angel and Kunkel (2010), using more than 500 runs from 23 GCMs under the SRES B1, A1B, and A2 emissions scenarios (Nakicenovic and Swart 2000), also suggests decline in annual lake levels. The projected median changes in lake levels for Lake Michigan-Huron for 2080-2094 were $-0.25,-0.28$, and $-0.41 \mathrm{~m}$ for the B1, A1B, and A2 scenarios, respectively. According to the projections of Hayhoe et al. (2010) under the SRES A1FI emissions scenarios, water level for Lake Michigan-Huron is expected to decline up to $0.60 \mathrm{~m}$.

Although various GCM runs under different emissions scenarios were considered in the "change factor" based studies, projected changes in the runoff from the terrestrial part of the Great Lakes basin in all these studies come from a single hydrological model (AHPS Large Basin Runoff Model; Croley 1983), which uses air temperature as a proxy for potential evapotranspiration (PET). As discussed by Lofgren et al. (2011), traditional hydrological models using this approach project an exaggerated evapotranspiration increase for future climate, and consequently runoff reduction, because of the absence of surface energy budget constraints in these models. Another important issue is that the AHPS does not account for the two-way exchange of energy and water between the Great Lakes basin and the overlying atmosphere, and therefore fails to capture important feedback processes occurring at the landand lake-atmosphere interfaces. Finally, the "change factor" method accounts only for changes in the mean (and eventually variance) and does not really grasp how the probability distribution function of climate variables will change in the future climate.

An alternative to the "change factor" method, not involving the AHPS or a temperature proxy for PET, is to use direct hydrological outputs of climate models that ensure energy and water conservation (Lofgren et al. 2013). Studies by Manabe et al. (2004) and Milly et al. (2005) based on GCM output suggest an increase in Great Lakes net outflow and consequently increasing water supply. Lofgren (2004) and MacKay and Seglenieks (2013), who promoted the use of Regional Climate Models (RCMs) in evaluating potential changes in the Great 
Lakes NBS, project less dramatic declines in water levels compared to "change factor" based studies. This study is a contribution to regional climate modeling effort over the Great Lakes region. It is expected that detailed regional characteristics represented in RCMs, including better depiction of the land surface spatial variability and processes, operating at a smaller scale will improve the reliability of the hydrological regime simulated over the Great Lakes. Our analysis includes a total of sixteen pairs of simulations generated with three different RCMs. These involve several numerical climate change experiments belonging to the North American Climate Change Regional Assessment Program (NARCCAP; Mearns et al. 2012), as well as an ensemble of simulations generated by the Canadian RCM Version 4 (CRCM4), over one of the operational domains known as AMNO (AMérique du Nord; see Music and Caya 2007), referred to as AMNO CRCM4 simulations. We first evaluate the RCM skill in simulating Great Lakes hydrological variables. Then the projected long-term changes in annual mean and seasonal cycles are addressed. Finally, an analysis of extremes values of the Great Lakes NBS is presented. The analysis is performed for each of the Great Lakes, but this work will focus on the results obtained for the Lake Michigan-Huron (MH) along with some discussion of the other lakes.

\section{RCM configuration and treatment of the Great Lakes in the NARCCAP and AMNO CRCM4 numerical experiments}

The following six RCMs developed by different research institutions have participated in the NARCCAP project: (i) CRCM4, (ii) RegCM3, (iii) WRFG, (iv) HadRM3, (v) MM5, and (vi) ECPC2. We used simulations from Phase 2 of the project, representing the historical (19712000) and future (2041-2070) periods, where each RCM was driven by two GCMs amongst the following four: (i) CGCM3, (ii) CCSM3, (iii) GFDL, and (iv) HadCM3. For model references, the reader is referred to Mearns et al. (2012). These NARCCAP CC simulations were generated with horizontal grid spacing of approximately $50 \mathrm{~km}$ over a domain covering most of North America (see Fig. 1 in Mearns et al. 2012). The SRES-A2 emissions scenario was applied for future climate runs. A total of six NARCCAP CC runs, generated with three different RCMs, archived all the variables needed for NBS analysis. These include the CRCM4 and WRFG, both driven by the CGCM3 and CCSM3, and the HadRM3 driven by the GFDL and HadCM3; these are hereafter abbreviated as NARCCAP CRCM4-CGCM3, CRCM4-CCSM, WRFG-CGCM3, WRFG-CCSM, HadRM3-GFDL and HadRM3-HadCM3.

The AMNO CRCM4 ensemble consists of ten pairs of present (1961-1999) and future (2041-2070) simulations generated with a 45-km grid. The AMNO domain covers North America entirely and part of the adjacent Pacific and Arctic Oceans. Lateral boundary conditions were taken from four different GCMs, including two versions of the Canadian GCM (CGCM2, Flato and Boer 2001; CGCM3, Scinocca et al. 2008), and two European GCMs: ECHAM5 (Jungclaus et al. 2006) and CNRM-CM3.3 (Salas-Melia et al. 2005). Note that five CGCM3 runs and three ECHAM5 runs, differing only in their initial conditions (often referred to as GCM members), are useful in illustrating the uncertainty associated with natural climate variability (Frigon et al. 2010; de Elía and Côté 2010). Greenhouse gas (GHG) concentrations over the future period follow the SRES-A2 scenario, with the exception of CNRM simulations, in which the SRES-A1B scenario is used. The latter is included in our ensemble because $\mathrm{CC}$ signal by the middle of this century is typically less sensitive to the choice of emissions scenario than to the driving GCM choice. Emissions scenario becomes increasingly important over longer time horizons.

Since water surface temperatures and lake ice concentrations are important drivers of the energy and water exchanges between the atmosphere and underlying lake surface, the 
Fig. 1 Observation-based (black and gray bars) and simulated annual means for the Michigan-Huron Basin over the 1971-1999 period for a screen air temperature over the lake, b lake evaporation and land evapotranspiration c over-lake and over-land precipitation $\mathbf{d}$ runoff from the land portion of the basin expressed as a water depth over the lake and NBS

simulated NBS will depend on the method used to calculate these variables in the RCM simulations. In the AMNO CRCM4 CC runs, a 1D interactive mixed-layer/thermodynamic-ice model (Goyette et al. 2000) is applied over the Great Lakes water grid points. The same lake model is also used in the NARCCAP CRCM4-CCSM simulations. In all other NARCCAP runs lake temperatures and lake ice over RCM water points are obtained from the nearest lake point of the driving GCM or, in the absence of lake, by spatially interpolating the GCM sea surface temperature from the adjacent oceans to the location of the lakes (for more details, see: http://www.narccap.ucar.edu/about/caveats.html).

\section{Great Lakes hydroclimatic conditions: annual means and seasonal cycles analysis}

\subsection{RCM evaluation}

\subsubsection{Data and methods}

Evaluation of RCMs skill in simulating the hydrological regime over the Great Lakes is carried out over a common period of the NARCCAP and AMNO CRCM4 present climate simulations (1971-1999) and is mainly based on the NOAA-GLERL monthly hydrometeorological database (Hunter et al. 2015), referred to as the GLM-HMD. The analysis involves validation of simulated annual means and mean seasonal cycles of the following variables: over-lake and over-land screen air temperatures, over-lake and over-land precipitation, lake evaporation and evapotranspiration from the adjacent land, runoff from the land part of the basin (expressed as a depth over the lake), and resulting NBS to a lake. The uncertainty estimates provided by Neff and Nicholas (2005) are used to represent the errors associated with observations.

Although GLM-HMD is compiled taking into account a huge amount of observations, some variables are still primarily based on calculations (Hunter et al. 2015). Thus, long-term monthly estimates of Great Lakes evaporation (1948-2010) are derived using Lake Evaporation Model (LEM; Croley 1989), whose input is a set of meteorological data based on near-shore over-land observations adjusted for over-water/over-ice conditions. Precipitation, air temperature and runoff estimates are based on NOAA National Climate Data Center (NCDC) and Environment Canada (EC) over-land gauges. A modified Thiessen Polygon approach is used to derive over-lake precipitation and air temperature, while Area Ratio Method (ARM) is applied for runoff estimation (for details, see Fry et al. 2013). The NBS is derived using the so-called component method: $N B S=$ $P_{L A K E}-E_{L A K E}+R$, where $P_{L A K E}, E_{L A K E}$ and $R$ are observation-based over-lake precipitation, lake evaporation simulated by LEM, and runoff from the land expressed as depth over the lake, respectively. Runoff from the land is converted to depth over the lake by multiplying its value by the area of the watershed divided by the area of the lake. Note that we also used the component method to calculate NBS from the raw RCM hydrological outputs. There is another observationbased NBS dataset useful for model evaluation, where the NBS is estimated indirectly as a residual in the water budget equation of the lakes: $N B S=\Delta S+O-I \pm D$. Here, $\Delta \mathrm{S}$ is the change in storage derived from the difference in observed lake levels at the beginning and the end of a month, $O$ is the outflow, $I$ is connecting channel inflow from the upstream lake, and $D$ is the man-made total diversion. Provisional monthly values of the residual NBS were provided by both EC and the U.S. 


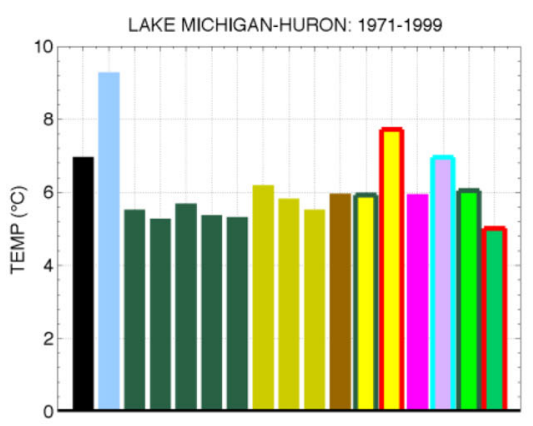

a)
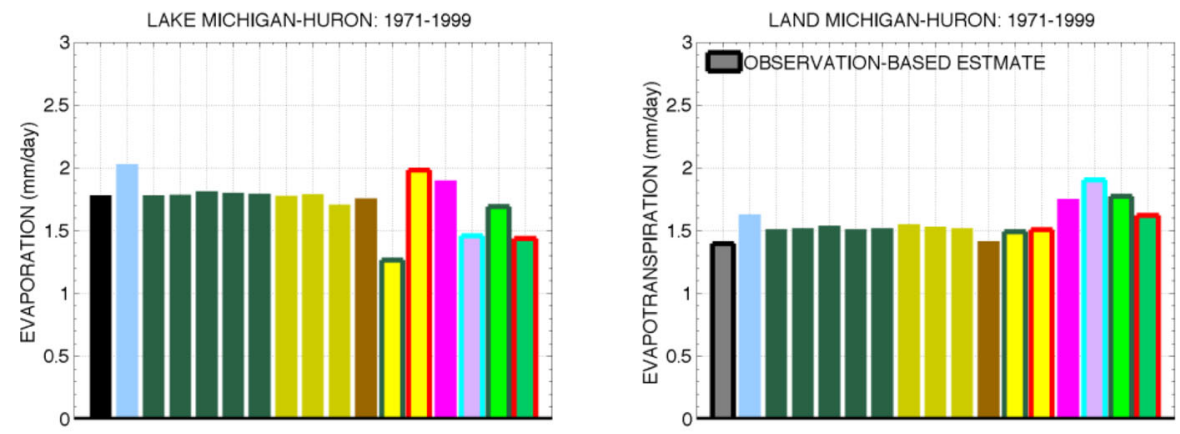

b)
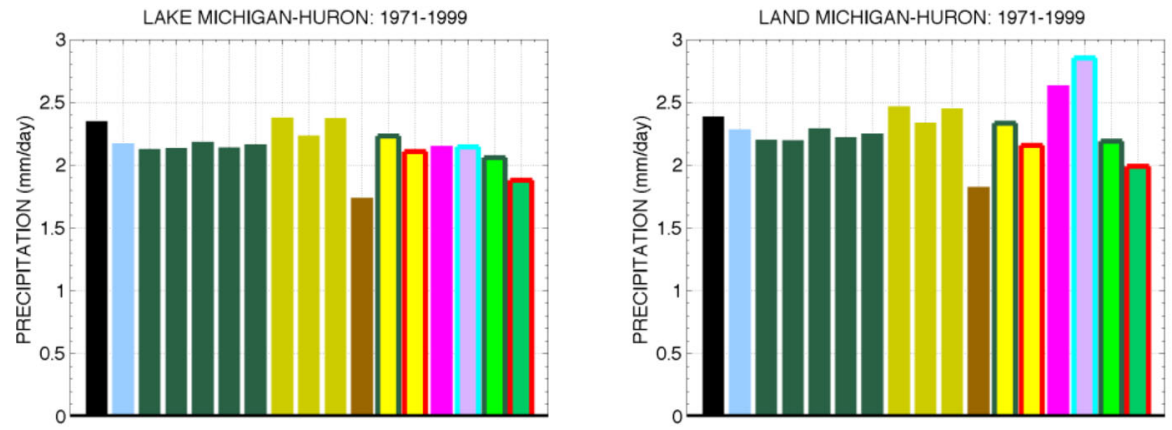

c)
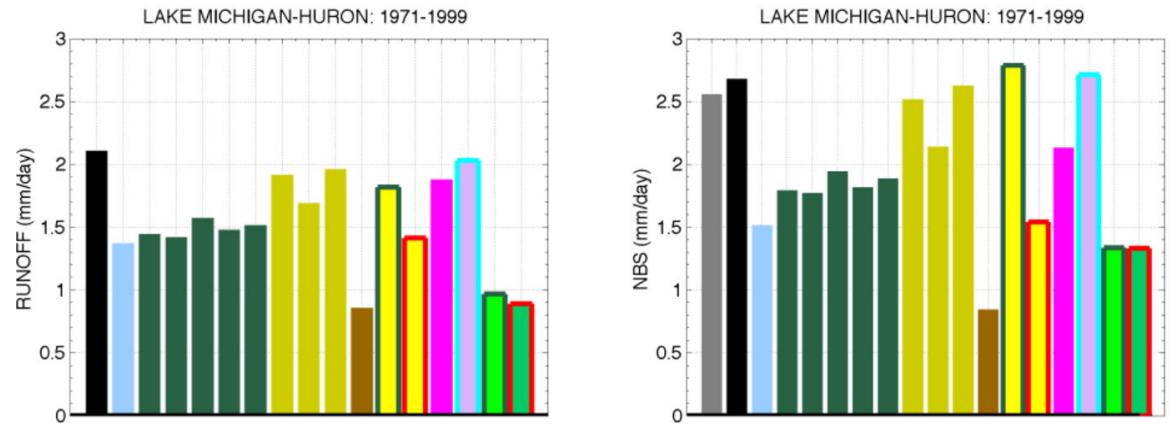

d) 
Army Corps of Engineers, which were subsequently agreed upon by Canada and U.S. and became values of the so-called coordinated residual NBS (Deacu et al. 2012). As GLM-HMD does not include evapotranspiration over the land part of the Great Lakes, we estimated the annual mean from the observation-based terrestrial water budget components (see Equation 7 in Music and Caya 2007). Note that only the long-term annual mean evapotranspiration can be derived using this method since annual variation in the terrestrial water storage averaged over a multiyear period can be neglected, which is not the case with water storage monthly variations (for more details, see Music and Caya 2007).

Observation-based estimates may involve an important uncertainty. Unfortunately, a limited number of quantitative studies addressing this question are available. Neff and Nicholas (2005) provided an approximate uncertainty assessment of all components involved in calculation of NBS for each of the Great Lakes. He found that residual NBS is not preferred in all situations despite the fact that the residual approach does not involve lake evaporation simulated by LEM. The main issue with the residual method is that connecting-channel flows and changes in storage can be very large compared to the NBS value, so that even a small uncertainty in flow and storage data can lead to a large uncertainty in the resulting residual NBS. The effect of connecting-channel flows on residual NBS uncertainty is amplified moving downstream through the system. For instance, for Lake Erie, the uncertainty in NBS for some months was found to be greater than the actual NBS estimate itself (Deacu et al. 2012).

\subsubsection{Results}

Figures 1 and 2 summarize the RCM skill in simulating the mean hydroclimatic conditions over the Lake MH. In general, RCMs tend to simulate colder annual mean screen air temperature over the lake compared to the GLM-HMD, with biases up to $-2.0{ }^{\circ} \mathrm{C}$ (Fig. 1a). Only the AMNO CRCM4-CGCM2 and the NARCCAP CRCM4-CCSM simulations show warm biases of $2.3{ }^{\circ} \mathrm{C}$ and $0.8{ }^{\circ} \mathrm{C}$, respectively. Similar model behavior is observed over the land part of the $\mathrm{MH}$ hydrological system (not shown). Cold biases in the RCM annual means are, in general, due to the underestimation of temperature from January to July (Fig. 2a). However, RCMs tend to simulate warmer than observed temperatures during late summer and fall.

Figure $1 \mathrm{~b}$ (left panel) shows evaporation from the Lake MH. The majority of simulations, on an annual scale, agree quite well with the GLM-HMD. Biases in the AMNO CRCM4 simulations are less than $10 \%$, however this is the result of the compensating effects of underestimation of evaporation in winter and overestimation in summer (Fig. 2b, left panel). Very cold winter and spring temperatures in most CRCM4 simulations produce extensive lakeice formation, reducing evaporative fluxes, resulting in significant underestimation of evaporation during winter. The period from April to June is characterized by relatively small lake evaporation in all simulations, which is consistent with GLM-HMD. This is related to the enhanced atmospheric stability over the lake during late spring and early summer, which is often called the "stable" Great Lakes season. It is well known that the relatively cool lake surface during this period of the year supports greater atmospheric stability (Notaro et al. 2013). The "unstable" Great Lakes season begins when lake surfaces become warmer than the surrounding land. The effect on the regional climate is most marked at the peak of the stable and unstable seasons, when the temperature differences between the over-lake and over-land surfaces are largest (Eichenlaub 1979). The stable and unstable seasons for Lake MichiganHuron are illustrated in Fig. 2a (right panel), where differences between the screen air lake and screen air land temperatures (Tlake-Tland) are represented from March to February; the green line shows the AMNO CRCM4 ensemble mean, while the pink dashed line represents the 

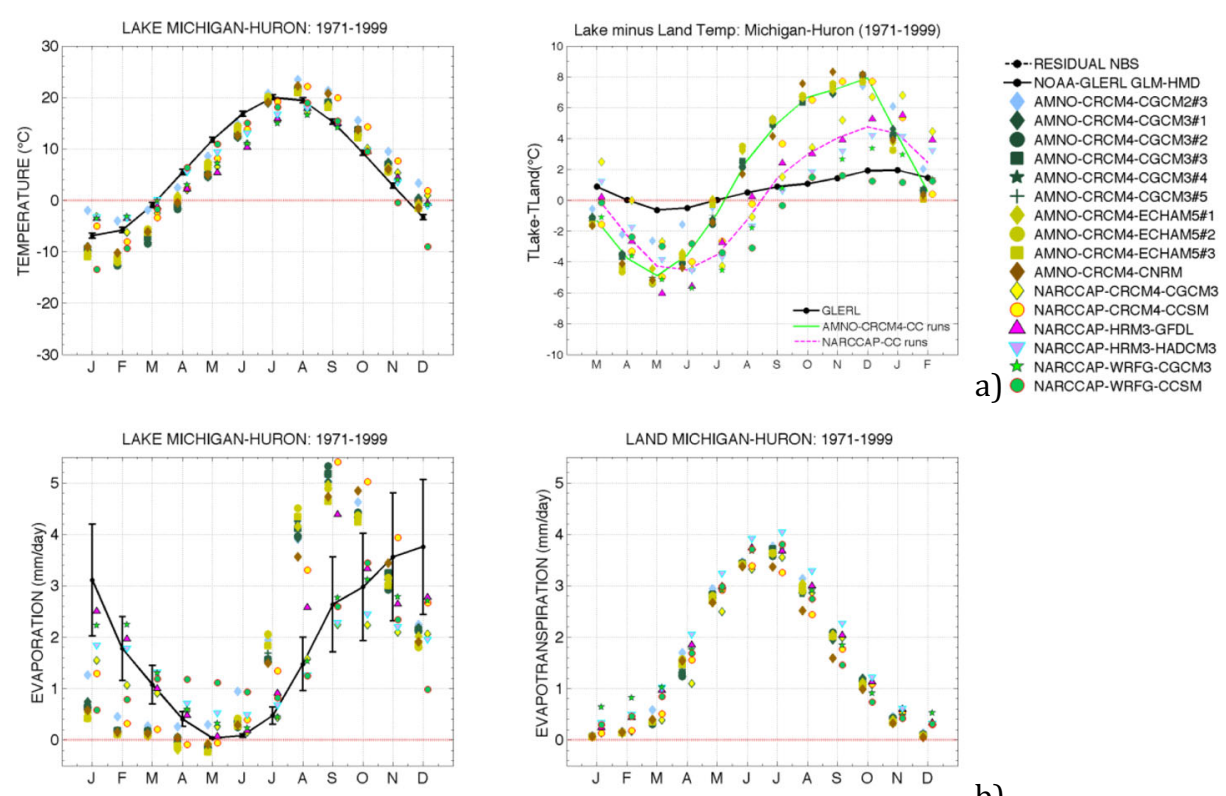

a) NARCCAP-WRFG-CGCM3
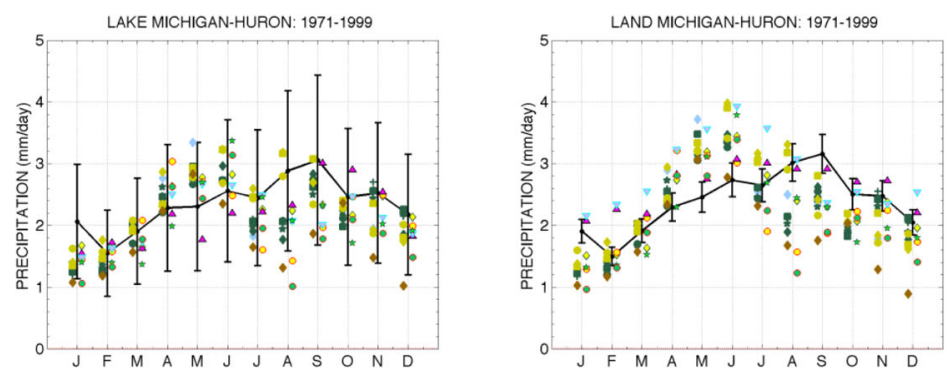

b)
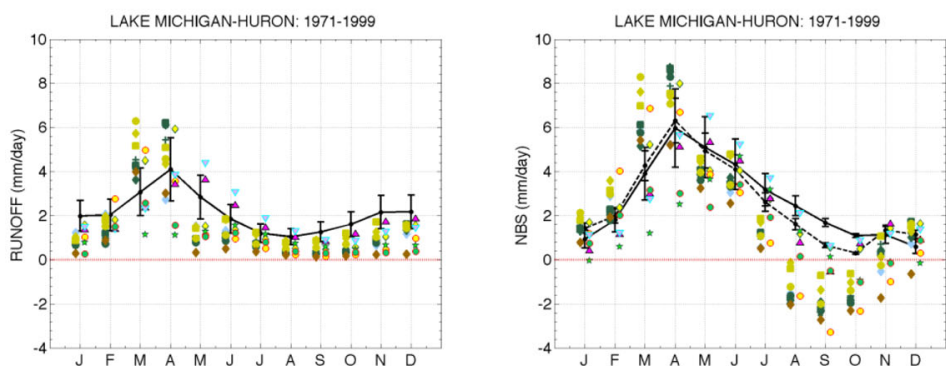

c)

d)

Fig. 2 Same as in Fig. 1, but for the mean seasonal cycle, excepting Fig 2a, right panel, where differences between the land and lake temperatures from March-February are shown. Black error bars represent the uncertainty related to observations, taken from Neff and Nicholas (2005). In the right panel of Fig. 2a, the green line shows the AMNO CRCM4 ensemble mean, while the pink dashed line is for the NARCCAP ensemble. In the right panel of Fig. 2d, the full black (dashed) line presents the component (residual) NBS estimates based on observations

NARCCAP ensemble. All models capture both seasons, but the RCM simulated lake-land temperature differences are much larger than those based on the GLM-HMD. In all CRCM4 
simulations based on the Goyette lake model, enhanced atmospheric instability over the lake during late summer and early fall is reflected in exaggerated evaporation compared to the GLM-HMD. The results of the HadRM3 and WRFG simulations are closer to GLM-HMD, with smaller annual amplitudes of the lake-land temperature contrast and smaller annual amplitudes of lake evaporation.

Land evapotranspiration simulated by the CRCM4 agrees very well with the observationbased annual mean (Fig. 1b, right panel), while it tends to be overestimated in the HadRM3 and WRFG simulations. It is interesting to note that the discrepancy between models in simulated evapotranspiration seasonal cycle (Fig. 2b, right panel) is much smaller than for lake evaporation (Fig. 2b, left panel), regardless of the differences in the RCMs land-surface parameterizations (Fig. 2a, right panel). Large differences in lake evaporation likely stem from different treatments of lake surface temperature among the models. Note also that the simulated seasonal cycles of evapotranspiration over the land and evaporation from the lake have opposite phases.

Regarding over-lake precipitation (Fig. 1c, left panel), biases in annual means exceed $10 \%$ in only 3 of the 16 simulations. The largest bias of $-26 \%$ is found in the AMNO CRCM4CNRM simulation. Similar skill is found with regards to the over-land annual mean. Simulated mean seasonal cycles for over-lake precipitation are generally within the bounds of the uncertainty associated with observation-based estimates, while they are not well captured for over-land precipitation (Fig. 2c, right panel). Note that the uncertainty estimate for over-lake precipitation provided by Neff and Nicholas (2005) is significantly larger (45\%) than for overland precipitation, which is considered to be around $10 \%$ in regions with high gauge network density. In general, RCMs tend to overestimate (underestimate) precipitation over the $\mathrm{MH}$ watershed during late spring (early fall).

Simulated annual mean runoff is greatly underestimated in the majority of simulations (Fig. 1d, left panel), with biases varying from -4 to $-60 \%$. Six simulations show runoff underestimations smaller than $20 \%$, including three AMNO CRCM4-ECHAM5, one NARC CAP CRCM4-CGCM3 and two NARCCAP HadRM3 runs. The seasonal cycle of runoff is best captured by the NARCCAP HadRM3 runs (Fig. 2d, left panel). The CRCM4 simulations tend to have an amplified runoff seasonal cycle due to spring overestimation and summer underestimation, while WRFG shows negative runoff biases all year round. Although the nonlinear nature of simulated climate processes makes it very difficult to isolate sources of these important biases in simulated runoff, this analysis indicates that RCM runoff may be very sensitive to the driving GCM, e.g., annual mean runoff simulated in the AMNO CRCM4CNRM run is more than two times smaller compared to the AMNO CRCM4-ECHAM5 runs. Recall that NARCCAP RCMs differ in structure and physical parameterizations, which results in notable differences in simulated seasonal cycles of the water budget components. Different representations of runoff generation, snow accumulation/melt and turbulent fluxes within the atmospheric boundary layer lead to different partitioning of simulated precipitation into runoff, evapotranspiration and terrestrial water storage (snow and/or soil moisture) change. Many approximations involved in representation of these very complex processes may lead to important biases in simulated hydrological variables.

Figures $1 \mathrm{~d}$ and $2 \mathrm{~d}$ (right panels) compare the Lake MH NBS derived from the raw RCM hydrological outputs with the observation-based residual NBS and GLM-HMD component NBS. Note that biases in annual NBS are generally related to biases in simulated runoff, while on seasonal time scale NBS values are very much determined by the biases in over-lake precipitation and evaporation, especially during autumn. The largest annual bias shows the AMNO CRCM4-CNRM simulation ( $-68 \%$ with respect to the averaged NBS estimates) due to both large underestimation of runoff and relatively small over-lake precipitation. Large NBS 
dry biases of approximately $-50 \%$ are also observed in the WRFG simulations, which are mainly due to very small runoff values. We note that the annual mean of the residual NBS for Lake MH is somewhat smaller than the GLM-HMD component NBS due to its smaller values during summer and early fall.

As mentioned in Section 1 this work is focused on Lake Michigan-Huron, however hydrological conditions over the other Great Lakes were analyzed likewise revealing a similar skill. Thus, cold temperature biases and related underestimation of winter lake evaporation, followed by late summer and fall temperature overestimation are common to all AMNO CRCM4 simulations. The NARCCAP WRFG simulations show consistently large negative runoff biases over all lakes. As well, the AMNO CRCM4-CNRM simulation is consistently too dry (too little precipitation and runoff). Regarding the resulting NBS, all models tend to simulate relatively small values during late summer and early fall, except for the NARCCAP simulations over Lake Erie, where NBS is overestimated.

\subsection{Climate change signal}

CC signal is assessed by computing differences between simulated future (2041-2070) and present (1971-1999) climate conditions. Looking at the difference allows the model biases to be partially reduced and should provide better projections (Frigon et al. 2010; de Elía and Côté 2010).

Figures 3 and 4 summarize the projected changes in annual and monthly means for Lake $\mathrm{MH}$. Note that projections from two NARCCAP simulations, HadRM3-GFDL and WRFGCCSM, are not included in the analysis. Surface water temperatures of the Great Lakes in these two numerical experiments were derived using different methods for present and future climate runs, which invalidates the use of the difference method employed here.

As shown in Figure 3a, projected changes in mean annual temperature over the Lake MH range from 2 to $3.6^{\circ} \mathrm{C}$. The AMNO CRCM4 simulations (as well as the NARCCAP CRCM4CCSM simulation, where the lake model was activated) tend to project slightly larger warming over the lake than over land. Projected warming is largest for the winter season (Fig. 4a), due to reduced lake ice and snow cover in the future climate (figure not shown). Warmer temperatures in future climate imply higher lake evaporation/land evapotranspiration. According to the ensemble median of both NARCCAP and AMNO CRCM4 simulations (pink and green lines on Fig. 3, respectively), annual evaporation from the lakes (Fig. 3b, left panel) increases more than evapotranspiration from the land (Fig. 3b, right panel). The AMNO CRCM4 simulations project the largest increases in lake evaporation in summer and early fall (Fig. $4 \mathrm{~b}$ left panel), which is partly related to earlier ice cover disappearance in future climate, allowing for faster warming of water surfaces. It is worth mentioning the work of Spence et al. (2013) who found that decreased ice cover, by itself, does not necessarily lead to enhanced annual evaporation losses. Instead, a combination of low ice cover and warm spring air temperature leads to an early breakup, which can significantly lengthen the next evaporation season and cause greater cumulative water loss the subsequent year.

Warmer climate and higher evaporation lead to an increase in annual mean precipitation of approximately $0.2 \mathrm{~mm} /$ day. While the majority of simulations project positive changes in precipitation from October to May (over both lake and land), there is no agreement on the sign of projected changes from June to September (Fig. 4c), resulting in an ensemble mean change close to zero during this period of the year.

Regarding the runoff change, 12 of the 14 runs considered project annual increases. However, net atmospheric water supply $(P-E)$ over the lake is projected to decrease in the future climate (evaporation increasing more than precipitation) on an annual time scale. 

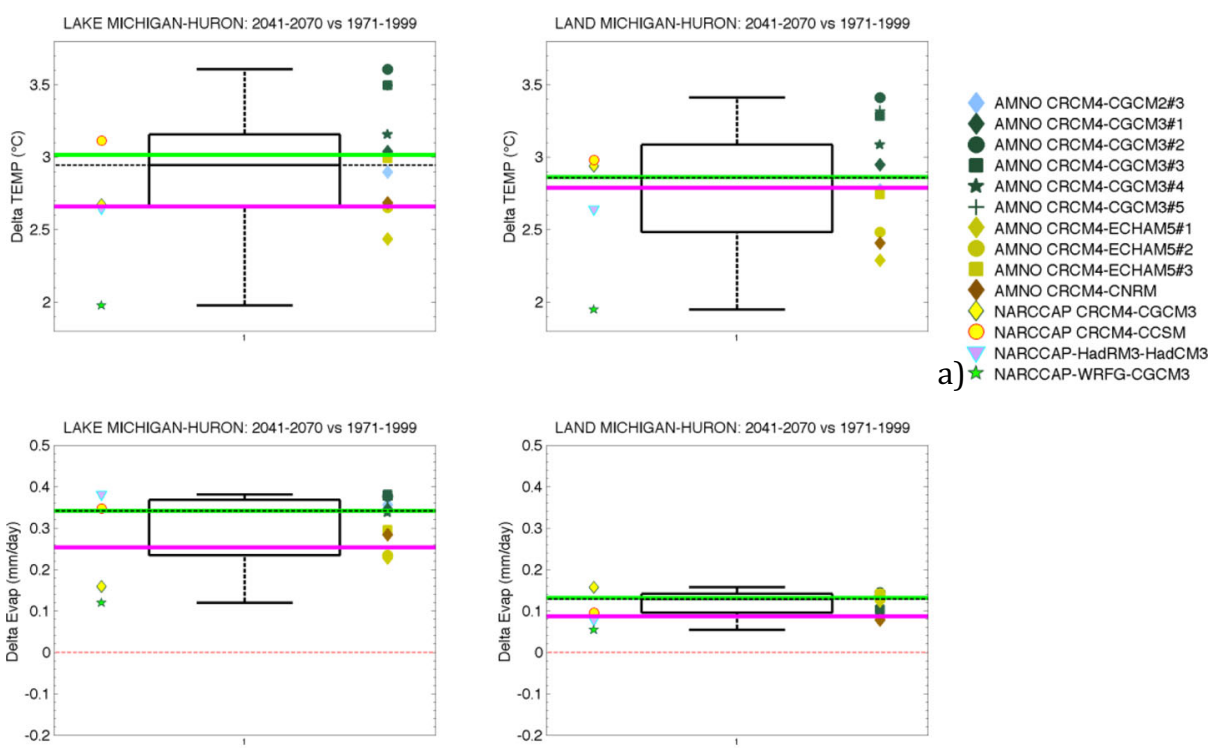

a)

NARCCAP-HadRM3-HadCM

a) NARCCAP-WRFG-CGCM3

b)
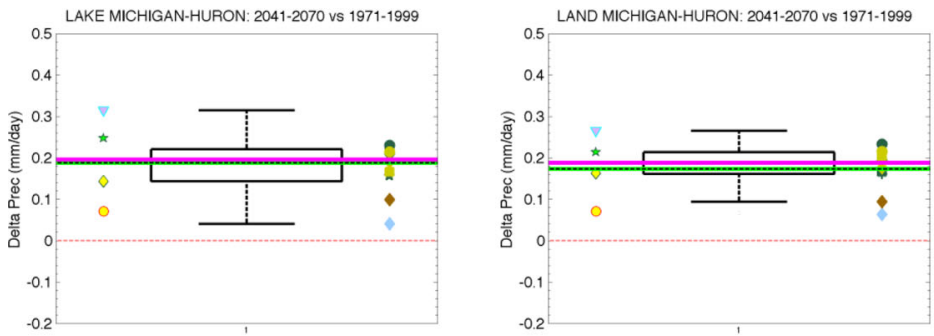

c)
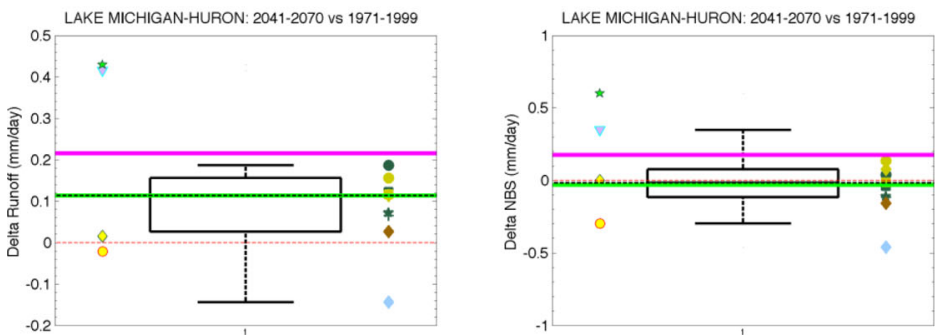

d)

Fig. 3 Projected annual changes for the Michigan-Huron Basin (1971-1999 to 2041-2070) of the a screen air temperature over the lake (left panel) and over the land part of the basin (right panel); b over-lake (left panel) and overland precipitation (right panel); $\mathbf{c}$ lake evaporation (left panel) and land evapotranspiration (right panel); $\mathbf{d}$ runoff from the land portion of the basin expressed as depth over the lake (left panel) and NBS (right panel). The black, green and pink horizontal lines represent ensemble median changes from all, the AMNO CRCM4, and NARCCAP simulations, respectively. The boxplot summarizes the results from all the AMNO CRCM4 and NARCCAP simulations

According to the AMNO CRCM4 ensemble median, this decrease is almost equal to the projected runoff increase, resulting in no change in NBS (green lines on Fig. 3d). Due to 

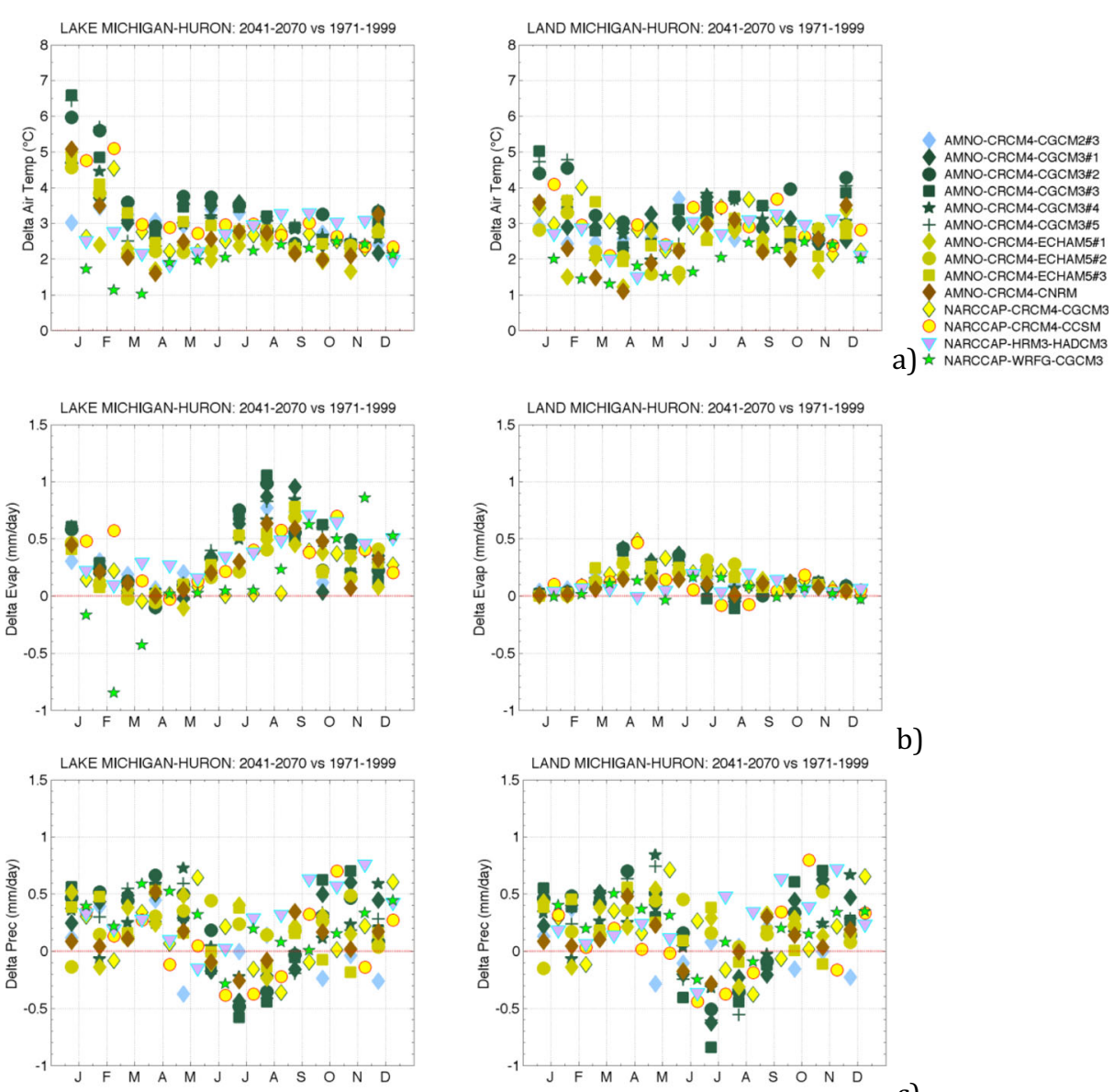

b)
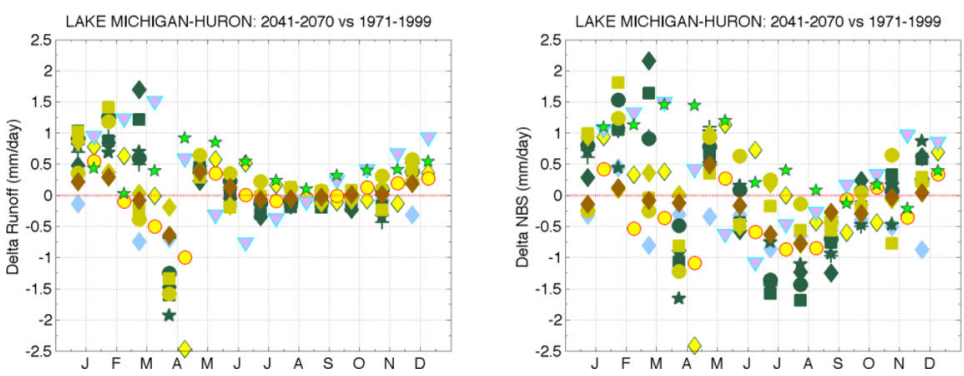

d)

Fig. 4 Projected monthly changes for the Michigan-Huron Basin from 1971-1999 to 2041-2070 of the a screen air temperature over the lake (left panel) and over the land portion of the basin (right panel); b over-lake (left panel) and over-land precipitation (right panel); $\mathbf{c}$ lake evaporation (left panel) and land evapotranspiration (right panel); $\mathbf{d}$ runoff from the land portion of the basin expressed as depth over the lake (left panel) and NBS (right panel). Symbols on the left (right) side for a given month correspond to the AMNO (NARCCAP) CC runs

relatively large runoff increases projected by the HadRM3 and WRFG simulations, the NARC CAP ensemble shows positive changes in annual NBS of approximately $0.2 \mathrm{~mm} /$ day. The total ensemble median (black line in Fig. 3d right panel) indicates no change in annual NBS. 
Regarding the NBS seasonal cycle change (right panel of Fig 4d), most simulations project a higher value from November to March and a smaller value from July to October, leading to a greater seasonal amplitude of NBS in future climate.

A decrease in future NBS in late summer and early fall is projected for all Great Lakes due to the decrease in both atmospheric (higher increase in lake evaporation than in over-lake precipitation) and land water supplies (land runoff). However, these water supplies tend to be higher during winter, resulting in higher NBS. Projected changes on an annual time scale fluctuate around zero, except for Lake Ontario for which most simulations (10 of 14) project NBS increases, with an ensemble mean of approximately $0.1 \mathrm{~mm} /$ day.

It is important to emphasize that the analysis presented in this section covers only a part of the uncertainties inherent in RCM simulations. These are related to the future GHG emissions, model imperfections (structural uncertainty) and natural climate variability. Improvement of both GCMs and RCMs is crucial in reducing the uncertainty of projected CC signal. However, uncertainty arising from natural variability, whose effects are illustrated in Fig. 3 through the spread between the five (three) AMNO CRCM4 simulations driven by different members of the CGCM3 (ECHAM5), is irreducible and would be present in a perfect climate model. In a recent study, Deser et al. (2012) demonstrated that natural climate variability accounts for at least half of the inter-model spread in projected climate trends for the 2050 horizon.

\section{NBS extreme analysis under the present and future climate conditions}

\subsection{Method}

Investigating possible changes in NBS extreme values, a series of annual NBS minima and maxima was constructed for both present and future periods using monthly NBS time-series. Annual minima and maxima were extracted by looking at the windows spanning from May to April, and from January to December, respectively, in order to ensure an appropriate extreme detection. The resulting annual minima and maxima series were then fitted to the Generalized Extreme Value (GEV) distribution (Coles 2001). From the fitted GEV distribution, the probability of exceedance (p) of a given NBS extreme quantile $\left(z_{p}\right)$ can be estimated (often called the return value or return level). $z_{p}$ is expected to be equaled or exceeded, on average, once every $1 / p$ years (period $T=1 / p$ is often called return period). For example, the 100 -year return level, or 0.99 quantile of the probability distribution, has a $1 \%$ chance of being exceeded in a given year. Note that GEV parameters are estimated using the Maximum Likelihood estimation (Coles 2001). We assume that the NBS time series over the present (1971-1999) and future (2041-2070) time windows is stationary. Therefore, the GEV parameters, and hence the probability of extreme events, are treated as a constant over each time-window. Results of the analysis are summarized in the so-called return level curves (return levels versus return periods), which are associated with $95 \%$ confidence intervals (Coles 2001).

\subsection{Results}

Figure 5 shows the return level curves and associated confidence intervals of the present and future climates (green and red lines, respectively) for the Lake Michigan-Huron NBS minima (Fig. 5a) and maxima (Fig. 5b). These are derived from fitted GEV distributions to the extreme NBS values coming from the AMNO CRCM4 simulations. Data used for fitting with the GEV distribution are represented with the open circles.

As can be seen from Fig. 5a, the red lines are located below the green lines for all ensemble members, suggesting that NBS minima can be expected to become more severe and more 
a
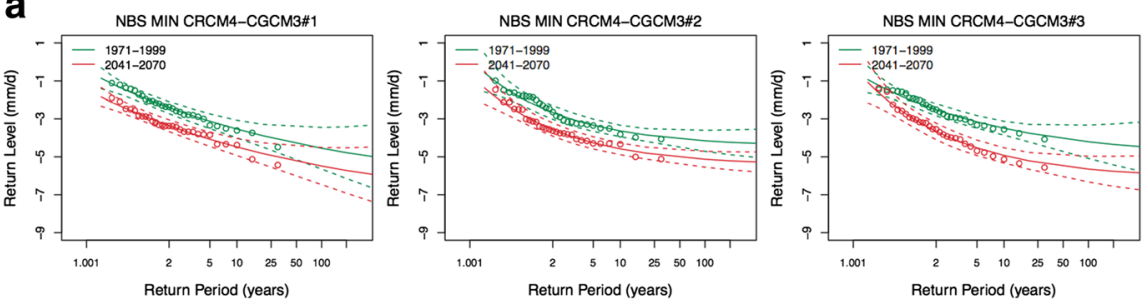

NBS MIN CRCM4-CGCM3\#4
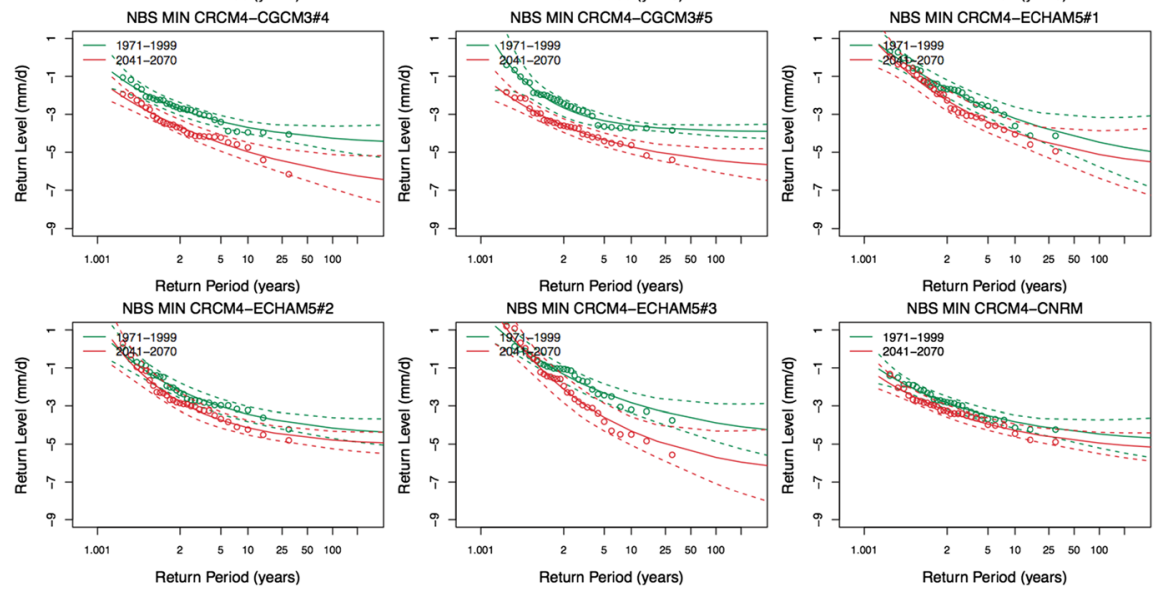

b
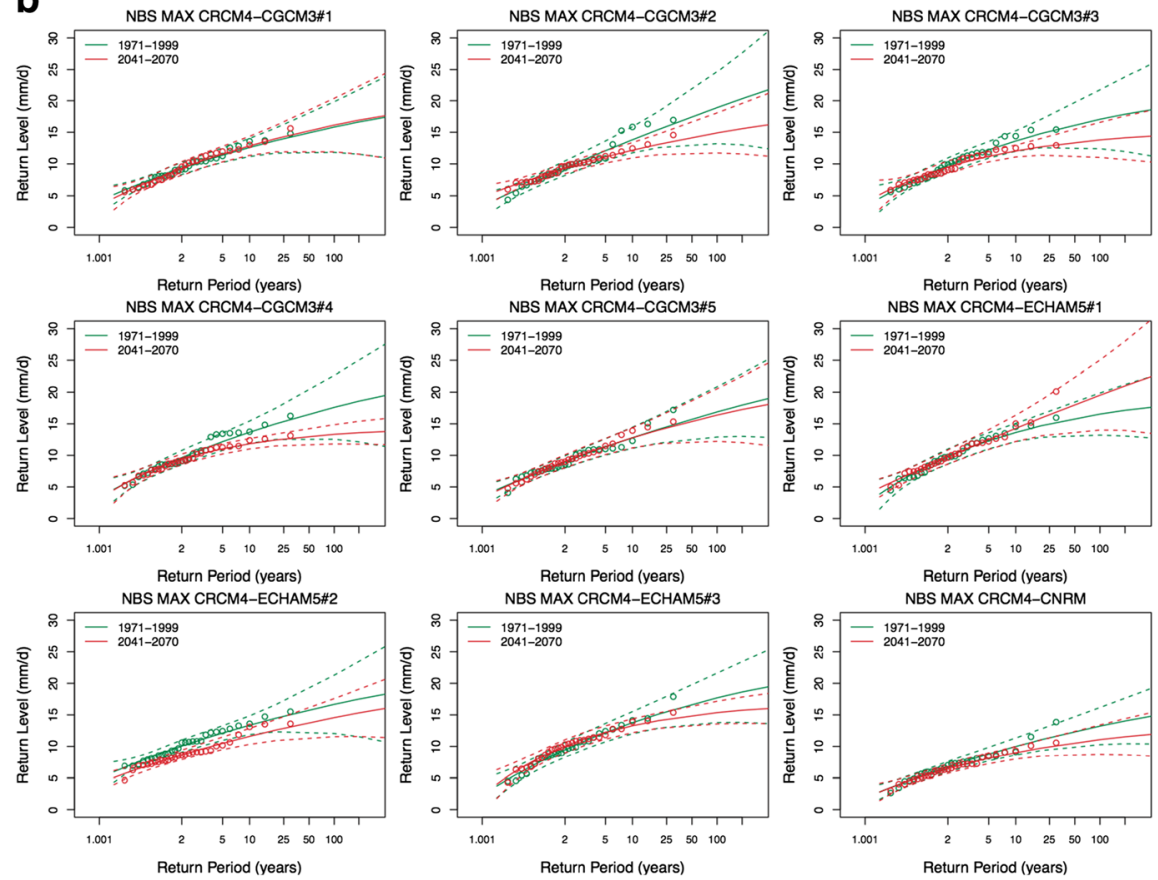

Fig. 5 Return level plots for the annual minima (a) and maxima (b) of monthly NBS over the 1971-1999 present (green) and 2041-2070 future (red) periods from the AMNO CRCM4 simulations. Full lines show return levels fitted to the GEV, with dashed lines for the $95 \%$ confidence intervals 
frequent in the future climate. The return plots derived from the NARCCAP ensemble (not shown) also suggest intensification of NBS minima in the future. By looking at the present and future return period of a specific return level, we can get an idea of how much more likely an extreme will become in the future. For example, a 10-year NBS minimum is likely to appear every 2 year by the middle of this century. This means that many of the present-day issues related to the low lake levels (e.g., commercial navigation) may worsen in future climate.

A decreasing trend is also found for the NBS maxima. Thus, six out of nine AMNO CRCM4 CC runs, as well as three out of four considered NARCCAP runs (not shown), project negative change in NBS maxima. However, Fig. 5b indicates that CC signal in NBS maxima is less clear because confidence intervals for the present and future climates tend to overlap. Note also that return levels corresponding to the longer return periods are associated with a larger uncertainty. Because time series used in this analysis covers relatively short time periods, return levels associated with long return periods should be interpreted with caution. Comparing Fig. 5a and b shows that NBS maxima are generally associated with much wider confidence intervals suggesting higher interannual variability in NBS maxima, which makes changes statistically less detectable.

\section{Concluding remarks}

Over the past several years there has been an increasing effort to include climate-change information in the Great Lakes water management strategy (IUGLS 2012). This requires a better understanding of the available hydroclimatic projections as well as the associated uncertainties and limitations. Studies based on "change factor" method applied to a suite of models generally lead to the conclusion that Great Lake water levels may significantly decline in future climate. However, RCM based studies suggest small decrease or even increase in the future levels (MacKay and Seglenieks 2013; Lofgren 2004). The present study complements existing efforts to quantify present and future Great Lakes NBS using RCMs.

The results of the analysis of an ensemble of six RCM simulations belonging to the NARC CAP project, supplemented by ten additional CRCM4 runs generated at Ouranos, have shown that significant efforts are needed to improve RCM's skill over the Great Lakes. Implementation of appropriate 3D lake modules that simulate not only vertical but also horizontal water transports is required to better capture lake surface conditions driving lake evaporation. Continuous efforts are also needed to improve the reliability of RCM runoff generation. Finally, it is important to keep in mind that biases in lateral boundary conditions coming from GCMs may significantly affect RCM precipitation and other water related variables. Therefore, GCM induced uncertainties need to be considered in RCM projections.

RCM projections on the annual time-scale for the Michigan-Huron NBS include both reductions and increases in NBS, resulting in median changes close to zero. An amplified annual cycle in future climate compared to the present, mainly due to reduced NBS during late summer and early fall, is projected for all Great Lakes. Finally, the analysis of NBS extremes suggests that annual minima of monthly NBS may become more severe and more frequent in the future climate.

Acknowledgments The authors wish to thank Michel Slivitzky (requiescat in pace) for many thoughtful discussions that greatly contributed to this study. The helpful comments provided by Andrew Gronewold and René Laprise are deeply appreciated. A special thanks goes to Mourad Labassi for technical support and to Barbara Casati for enriching discussions on extreme values theory. We also acknowledge the editor and the three anonymous reviewers for their constructive comments and suggestions. Authors are grateful to NOAA-GLERL and NARCCAP for providing the data used in this paper. The CRCM4 data has been generated by the Ouranos Climate Simulation and Analysis Group. 
Open Access This article is distributed under the terms of the Creative Commons Attribution License which permits any use, distribution, and reproduction in any medium, provided the original author(s) and the source are credited.

\section{References}

Angel J, Kunkel KE (2010) The response of Great Lakes water levels to future climate scenarios with an emphasis on Lake Michigan-Huron. J Great Lakes Res 36:51-58

Coles S (2001) An introduction to statistical modeling of extreme values. Springer, London, U.K., 208 pp

Croley TE II (1990) Laurentian Great Lakes double — CO2 climate change hydrological impacts. Clim Chang 17:27-47

Croley T (1989) Verifiable evaporation modeling on the Laurentian Great Lakes. Water Resour Res 25(5):781-792

Croley TE II (1983) Great Lake basins (U.S.A.-Canada) runoff modeling. J Hydrol 64:135-158

Deacu D, Fortin V, Klyszejko E, Spence C, Blanken PD (2012) Predicting the net basin supply to the Great Lakes with a hydrometeorological model. J Hydrometeorol 13(6):1739-1759

de Elía R, Côté H (2010) Climate and climate change sensitivity to model configuration in the Canadian RCM over North America. Meteorol Z 19(4):325-339

Deser CA, Phillips S, Bourdette V, Teng H (2012) Uncertainty in climate change projections: the role of internal variability. Clim Dyn 38:527-546

Eichenlaub VL (1979) Weather and climate of the Great Lakes Region. University of Notre Dame Press, South Bend, IN, $335 \mathrm{pp}$.

Flato GM, Boer GJ (2001) Warming asymmetry in climate change simulations. Geophys Res Lett 28:195-198

Frigon A, Music B, Slivitzky M (2010) Sensitivity of runoff and projected changes in runoff over Quebec to the update interval of lateral boundary conditions in the Canadian RCM. Meteorol Z 19(3):225-236

Fry LM, Hunter TS, Phanikumar MS, Fortin V, Gronewold AD (2013) Identifying streamgage networks for maximizing the effectiveness of regional water balance modeling. Water Resour Res 49:1-12

Gronewold AD, Clites AH, Hunter TS, Stow CA (2011) An appraisal of the Great Lakes advanced hydrologic prediction system. J Great Lakes Res 37(3):577-583

Goyette S, McFarlane NA, Flato G (2000) Application of the Canadian Regional Climate Model to the Laurentian Great Lakes regions. Implementation of a lake model. Atmos - Ocean 38:481-503

Hartmann HC (1988) Historical basis for limit on Lake Superior water level regulations. J Great Lakes Res 14(3): 316-324

Hartmann HC (1990) Climate change impacts on Laurentian Great Lakes levels. Clim Chang 17:49-67

Hayhoe K, VanDorn J, Croley TE, Schlegal N, Wuebbles D (2010) Regional climate change projections for Chicago and the US Great Lakes. J Great Lakes Res 36:7-21

Hunter TS, Clites AH, Campbell KB, Gronewold AD (2015). Development and application of a monthly hydrometeorological database for the North American Great Lakes - Part I: precipitation, evaporation, runoff, and air temperature. J Great Lakes Res. In Press, Corrected Proof, Available online 7 February 2015. http://www.sciencedirect.com/science/article/pii/S0380133014002676

IUGLS (2012) Lake superior regulation: addressing uncertainty in Upper Great Lakes Water levels. Final Report to the International Joint Commission

Jungclaus JH, Botzet M, Haak H, Keenlyside N, Luo J-J, Latif M, Marotzke J, Mikolajewicz U, Roeckner E (2006) Ocean circulation and tropical variability in the AOGCM ECHAM5/MPI-OM. J Clim 19(16):3952-3972

Lofgren B, Quinn F, Clites A, Assel R, Eberhardt A, Luukkonen C (2002) Evaluation of potential impacts on Great Lakes water resources based on climate scenarios of two GCMs. J Great Lakes Res 28(4):537-554

Lofgren BM, Hunter TS, Wilbarger J (2011) Effects of using air temperature as a proxy for potential evapotranspiration in climate change scenarios of Great Lakes basin hydrology. J Great Lakes Res 37(4):744-752

Lofgren BM (2004) Global warming effects on Great Lakes water: more precipitation but less water? Proceedings, 84th annual meeting of the american meteorological society, Seattle, 11-15 January 2004. American Meteorological Society

Lofgren BM, Gronewold AD, Acciaioli A, Cherry J, Steiner AL, Watkins DW (2013) Methodological approaches to projecting the hydrologic impacts of climate change. Earth Interact 17(22):1-19

MacKay M, Seglenieks F (2013) On the simulation of Laurentian Great lakes water levels under projections of global climate change. Clim Chang 117:55-67

Manabe, Wetherald RT, Milly PCD, Delworth TL, Stouffer RJ (2004) Century-scale change in water availability: CO2-quadrupling experiment. Clim Chang 64:59-76

Mearns LO, Arritt R, Biner S et al (2012) The north American regional climate change assessment program: overview of phase I results. Bull Am Meteorol Soc 93:1337-1362 
Milly PCD, Dunne KA, Vecchia AV (2005) Global pattern of trends in streamflow and water availability in a changing climate. Nature 438:347-350

Music B, Caya D (2007) Evaluation of the hydrological cycle over the Mississippi River Basin as simulated by the Canadian Regional Climate Model (CRCM). J Hydrometeorol 8(5):969-988

Nakicenovic N, Swart R (eds) (2000) IPCC special report on emissions scenarios: a special report of Working Group III of the IPCC. Cambridge University Press, Cambridge, p 599

Neff BP, Nicholas JP (2005) Uncertainty in the Great Lakes water balance: USGS scientific investigations report 2004-5100, 42 pp (http://pubs.usgs.gov/sir/2004/5100)

Notaro M, Holman K, Zarrin A, Fluck E, Vavrus S, Bennington V (2013) Influence of the Laurentian Great Lakes on regional climate. J Clim 26(3):789-804

Salas-Melia D, Chauvin F, Deque M, Douville H, Gueremy JF, Chauvin F, Planton S, Royer JF, Tyteca S (2005) Description and validation of the CNRM-CM3 global coupled model, CNRM Tech. Rep. 103

Scinocca JF, McFarlane NA, Lazare M, Li J, Plummer D (2008) Technical note :the CCCma third generation AGCM and its extension into the middle atmosphere. Atmos Chem Phys 8:7055-7074

Spence C, Blanken P, Hedstrom N, Fortin V, Wilson H (2013) Evaporation from Lake Superior: 2: spatial distribution and variability. J Great Lakes Res 37(4):717-724 